\title{
Hepatitis B and Hepatitis C among Human Immunodeficiency Virus Infected Patients at a District Hospital in Mwanza, Tanzania
}

\author{
Mariam M. Mirambo ${ }^{1 *}$, Benson R. Kidenya ${ }^{2}$, Vitus Silago', Emmanuel Mkumbo1, \\ Awadh Mujuni ${ }^{1}$, Kennedy J. Mmanga ${ }^{1}$, Japhet J. Mwihambi ${ }^{1}$, Shimba Henerico ${ }^{3}$, \\ Carolyne A. Minja ${ }^{2}$, Stephen E. Mshana ${ }^{1}$
}

\author{
${ }^{1}$ Department of Microbiology and Immunology, Weill Bugando School of Medicine, Catholic University of Health and Allied \\ Sciences, Mwanza, Tanzania \\ ${ }^{2}$ Department of Biochemistry and Molecular Biology, Weill Bugando School of Medicine, Catholic University of Health \\ and Allied Sciences, Mwanza, Tanzania \\ ${ }^{3}$ Bugando Medical Centre, Mwanza, Tanzania \\ Email: *mmmira mbo@gmail.com
}

How to cite this paper: Mirambo, M.M., Kidenya, B.R., Silago, V., Mkumbo, E., Mujuni, A., Mmanga, K.J., Mwihambi, J.J., Henerico, S., Minja, C.A. and Mshana, S.E. (2019) Hepatitis B and Hepatitis C among Human Immunodeficiency Virus Infected Patients at a District Hospital in Mwanza, Tanzania. World Journal of AIDS, 9, 1-10. https://doi.org/10.4236/wja.2019.91001

Received: December 11, 2018

Accepted: January 19, 2019

Published: January 22, 2019

Copyright $\odot 2019$ by author(s) and Scientific Research Publishing Inc. This work is licensed under the Creative Commons Attribution International License (CC BY 4.0).

http://creativecommons.org/licenses/by/4.0/

\section{(c) (i) Open Access}

\begin{abstract}
Human immunodeficiency virus (HIV), hepatitis B virus (HBV) and Hepatitis $\mathrm{C}$ virus (HCV) infections have been a major public health problem. HIV patients with HBV and HCV infection are at high risk of liver diseases which is associated with increased mortality. This study aims at determining the prevalence of hepatitis B surface antigen ( $\mathrm{HBsAg}$ ), HCV antibodies and HBV antibodies (anti-HBsAg) among HIV seropositive adults attending care and treatment clinic at Sengerema district hospital in Mwanza, Tanzania. A cross-sectional hospital based study was conducted between February and March 2017 among 243 HIV adult patients at Sengerema designated district hospital, Mwanza, Tanzania. Socio-demographic and other relevant information were collected using pre-tested questionnaires. Detection of HBsAg and HCV antibodies was done by commercial rapid immunochromatographic test while the detection of anti-HBsAg was done using enzyme linked immunosorbent assay. Data were analyzed by using STATA version 13 . The median age of the study participants was 43, interquartile range (IQR): 37 - 51 years. The majority 172 (70.8) of study participants were female and the majority (88\%) of participants had CD4 count of greater than 200 counts/ $\mu$ l. The prevalence of $\mathrm{HBsAg}, \mathrm{HCV}$ antibodies and anti-HBsAg were $26 / 243(10.7 \%$, 95\% confidence interval [CI]: 7 - 14), 20/243 (8.2\%, 95\% CI: 4.7 - 11.6) and (100/243) 41.2\%, 95\% CI: 35 - 47, respectively. Co-infection with HCV (OR: 4.45, 95\% CI: $1.51-13.21, \mathrm{P}=0.007)$ was independenlty found to predict HbsAg positivity. History of blood transfusion (OR: 2.34, 95\% CI: 1.08 - 5.06,
\end{abstract}


$\mathrm{P}=0.028$ ) was significantly associated with anti-HBsAg among HIV infected individuals while, the rate of anti-HBsAg was found to decrease by $2.02 \mathrm{IU} / \mathrm{L}$ in a year increase in age. About one tenth of HIV infected individuals are co-infected with HCV and HBV with more than one third being positive for anti-HBsAg. There is a paramount need to emphasize the need for regular screening and proper management of these patients to reduce associated complications in resource limited countries where these infections are common.

\section{Keywords}

Hepatitis B, Hepatitis C, HIV, Sengerema, Tanzania

\section{Introduction}

Human immunodeficiency virus (HIV), hepatitis B virus (HBV) and Hepatitis C virus (HCV) infections have been a major public concern because they do share the same route of transmissions and the risk groups are believed to be exposed to the viruses more/less simultaneously [1] [2] [3]. In the sub-Saharan Africa, it is believed that the majority of people are being exposed to HBV at the age of five years before being exposed to HIV infection when they become sexually active $[2]$.

WHO estimated 2 billion persons worldwide who have been infected with HBV. It is the cause of up to $50 \%$ of hepatocellular carcinomas (HCC). The World Health Organization (WHO) estimated that more than 686,000 individuals died worldwide in 2016 due to $\mathrm{HBV}$-associated acute and chronic liver disease. HBV viral infection is the highest in the sub-Saharan Africa and East Asia, where $5 \%$ to $10 \%$ of the adult population is chronically infected [4]. On the other hand, WHO estimates that about 150 million people ( $3 \%$ of the world's population) are chronically infected with HCV, with $3-4$ million newly infected individuals each year [5]. Africa has a major share of this burden, accounting for 31.9 million infections and the highest prevalence of $5.3 \%$ [6], compared to South East Asia and Middle East with $2.15 \%$ and $4.6 \%$, respectively while America and Europe have prevalence's less than $2 \%$ [5]. HCV is responsible for about 350,000 deaths annually; among western countries, southern Europe and particularly Italy [7].

There are few studies done to evaluate the presence of anti-HBsAg among HIV seropositive individuals. The prevalence of anti-HBsAg has been found to range from $31.9 \%$ in general population to $67.8 \%$ in intravenous drug users [3] [8] [9]. Whereas, the prevalence of hepatitis $C$ in the general population in the sub-Saharan Africa has recently been estimated to be 3\% [6] while that among HIV individuals has been found to range from $0.6 \%$ in Zimbabweto $18.1 \%$ in Tanzania [10] [11] [12]. The information about the magnitude HBV and HCV among HIV population is scarce in rural settings of Mwanza; therefore this 
study was done to determine the prevalence of $\mathrm{HBsAg}, \mathrm{HCV}$ and anti-HBsAg HBV among HIV positive individuals at Sengerema district hospital, Mwanza, Tanzania.

\section{Methodology}

\subsection{Study Design}

A cross sectional hospital based study was conducted among HIV/AIDS seropositive adults who visited the study site from January to February 2017.

\subsection{Study Area}

The study was conducted at care and treatment centre (CTC) at Sengerema designated District Hospital (SDDH). This is a large mission hospital in Sengerema district, Mwanza Province, which was founded in 1959. The hospital has approximately 300 bed capacity, divided into nine departments. There is a maternity/pregnant department, delivery rooms, a children's department, an internal department for men and women, a surgical department for men and women, eye ward and a private section. There are also several large polyclinics (outpatient department), including a dentist, eye doctor, physiotherapy, TB clinic and a large CTC clinic. Furthermore, the hospital has a pharmacy, a small laboratory, three operating rooms and an X-ray department. The hospital is serving about 400 people per day, giving treatment and follow-up for up to 60 HIV/AIDS seropositive adult patients per day, and about 30 children on Saturdays.

\subsection{Sample Size, Data Collection, Sampling}

The sample size was estimated using Kish Lisle (1965) formula; the prevalence of $18.1 \%$ from the study conducted at Muhimbili National Hospital [13] was used. All HIV adult infected individuals including pregnant women attended CTC clinic at Sengerema DDH were conveniently included in the study. The study excluded individuals of less than 18 years. Data collection was done on a daily basis from Monday to Friday by using pre-tested data collection tool. Simple random technique was used whereby small pieces of paper was prepared with letters YES or NO, clients was then told to pick up the piece of paper before attending the services. Only clients with a paper written YES were interviewed after signing a written informed consent and blood obtained for HBsAg and HCV antibodies detection using commercial rapid immunochromatographic tests (ACON laboratories, Inc., CA92121, USA) and anti-HBsAg using enzyme linked immunosorbent assay (SIEMENS-Enzygnost anti-HBsAg II, Marburg/Germany).

\subsection{Data Analysis}

Continuous variables were presented as median with inter-quartile range while categorical variables were presented as proportions. For HbsAg and $\mathrm{HCV}$ univariate analysis using Chi square and Fischers exact test was done followed by multivariate logistic regression analysis to determine the predictors of $\mathrm{HbsAg}$ 
and HCV for the factors with $\mathrm{P}$ value less than 0.2. For anti-HBsAg Univariate logistic analysis was done follwed by multivariate analysis of the factors with $\mathrm{P}$ value less than 0.2. All factors with $\mathrm{P}$-values of $<0.05$ at $95 \%$ confidence interval were considered statistically significant. Scatter diagram with line fit was used to show relationship between anti-HBsAg titers with age.

\subsection{Ethical Approval}

Ethical clearance for conducting this study was sought from CUHAS/BMC research ethics and review committee (CREC) with certificate number: CREC/38$8 / 2017$.

\section{Results}

\subsection{Sociodemographic and Clinical Information of the Study Participants}

A total of 243 HIV seropositive individuals attending CTC were enrolled with the median age of 43 , interquartile range (IQR): 37 - 51 years. The majority 172 (70.8\%) of study participants were female. A total of 36/243 (14.8\%) participants had history of blood transfusion, while a significant proportion 81/243 (33.33\%) reported to have history of sexually transmitted infections (STIs) (Table 1).

Table 1. Demographic characteristics of the 243 HIV seropositive unvaccinated individuals against $\mathrm{HBV}$ at Sengerema DDH.

\begin{tabular}{|c|c|c|}
\hline Participant characteristics & Number & Percent (\%)/Median \\
\hline Age (Years) & 243 & 44 (IQR: 18 - 75) \\
\hline \multicolumn{3}{|l|}{ Sex } \\
\hline Male & 71 & 29.22 \\
\hline Female & 172 & 70.78 \\
\hline \multicolumn{3}{|l|}{ Transfusion } \\
\hline Yes & 36 & 14.81 \\
\hline No & 207 & 85.19 \\
\hline \multicolumn{3}{|l|}{ STI } \\
\hline Yes & 81 & 33.33 \\
\hline No & 162 & 66.67 \\
\hline \multicolumn{3}{|l|}{ Drug use } \\
\hline Yes & 4 & 1.65 \\
\hline No & 239 & 98.35 \\
\hline \multicolumn{3}{|l|}{ Tatooing } \\
\hline Yes & 191 & 78.60 \\
\hline No & 52 & 21.40 \\
\hline \multicolumn{3}{|l|}{ Sharing devices } \\
\hline Yes & 15 & 6.17 \\
\hline No & 228 & 93.83 \\
\hline \multicolumn{3}{|l|}{ Last $\mathrm{CD}_{4}$ counts } \\
\hline$<200$ cells $/ \mathrm{mm}^{3}$ & 29 & 11.9 \\
\hline $200-500$ cells $/ \mathrm{mm}^{3}$ & 123 & 50.6 \\
\hline$>500$ cells $/ \mathrm{mm}^{3}$ & 91 & 37.4 \\
\hline
\end{tabular}




\subsection{Prevalence of HCV, HBsAg and Anti-HBsAg}

The prevalence of HBsAg, HCV antibodies and anti-HBsAg were found to be 26/243 (10.7\%, 95\% CI: 7 - 14), 20/243 (8.2\%, 95\% CI: 4.7 - 11.6) and 100/243 (41.2\%, 95\% CI: 35 - 47) respectively.

\subsection{Factors Associated with HBsAg Positivity}

Out of 20 patients with $\mathrm{HCV}$ antibodies, 6 (30\%) were $\mathrm{HbsAg}$ positive compared to $8.97 \%$ of 223 who were HCV antibodies negative $(\mathrm{P}=0.004)$. Other factors studied in Table 2 were not found to be associated with HbsAg positivity. By multivariate logistic regression analysis only coinfection with HCV (OR: 4.45, 95\% CI:1.51 - 13.21, $\mathrm{P}=0.007$ ) was found to predict HbsAg positivity.

Table 2. Factors associated with HBsAg positivity among HIV seropositive adult patients at Sengerema DDH.

\begin{tabular}{|c|c|c|c|c|c|c|}
\hline \multirow[b]{2}{*}{ Variable } & \multirow[b]{2}{*}{$\begin{array}{c}\text { HBV } \\
\text { (Negative) }\end{array}$} & \multirow[b]{2}{*}{$\begin{array}{c}\text { HBV } \\
\text { (Positive) }\end{array}$} & \multicolumn{2}{|c|}{ Univariate regression } & \multicolumn{2}{|c|}{ Multivariate regression } \\
\hline & & & $\begin{array}{c}\text { Chi } \\
\text { square/fisher's } \\
\text { exact }\end{array}$ & $\mathrm{P}$-value & OR $[95 \% \mathrm{CI}]$ & P-value \\
\hline Sex & $\begin{array}{l}\text { Median\% } \\
\text { (IQR) }\end{array}$ & $\begin{array}{c}\text { Median\% } \\
\text { (IQR) }\end{array}$ & & & & \\
\hline Male & $65[91.55]$ & $6[8.45]$ & & & & \\
\hline Female & $152[88.37]$ & $20[11.63]$ & 0.5309 & 0.466 & $1.41[0.43-3.7]$ & 0.486 \\
\hline \multicolumn{7}{|l|}{ Transfusion } \\
\hline No & 185 [89.37] & $22[10.63]$ & & & & \\
\hline Yes & 32 [88.89] & $4[11.11]$ & 0.0075 & 0.931 & & \\
\hline \multicolumn{7}{|l|}{ STI } \\
\hline No & $145[89.51]$ & 17 [10.49] & & & & \\
\hline Yes & $72[88.89]$ & 9 [11.11] & 0.0215 & 0.883 & & \\
\hline \multicolumn{7}{|l|}{ Drug user } \\
\hline No & $214[89.54]$ & $25[10.46]$ & & & & \\
\hline Yes & $3[75]$ & $1[25]$ & 0.8705 & 0.351 & & \\
\hline \multicolumn{7}{|l|}{ Tatoos } \\
\hline No & $49[94.23]$ & $3[5.77]$ & & & & \\
\hline Yes & $168[87.96]$ & $23[12.04]$ & 1.6831 & 0.195 & $2.1[0.59-7.42]$ & 0.248 \\
\hline \multicolumn{7}{|l|}{$\begin{array}{l}\text { Sharing } \\
\text { devices }\end{array}$} \\
\hline No & $205[89.91]$ & $23[10.09]$ & & & & \\
\hline Yes & $12[80.00]$ & $3[20.00]$ & 1.4473 & 0.229 & & \\
\hline \multicolumn{7}{|l|}{$\mathrm{HCV}$} \\
\hline Negative & 203 [91.03] & $20[8.97]$ & & & & \\
\hline Positive & $14[70.00]$ & $6[30.00]$ & & 0.004 & $\begin{array}{c}4.45 \\
{[1.51-13.21]}\end{array}$ & 0.007 \\
\hline Age & $217[89.30]$ & $26[10.70]$ & $44.2[42.8-45.6]$ & 0.384 & $\begin{array}{c}0.97 \\
{[0.94-1.01]}\end{array}$ & 0.312 \\
\hline
\end{tabular}




\subsection{Factors Associated with HCV}

On univariate analysis, female $8.7 \%$ (15/172) were more infected by HCV than male counterparts $7 \%(5 / 71)$, however this association was not statistically significant $(\mathrm{P}=0.665)$.

\subsection{Factors Associated with Anti-HBsAg}

The level of anti-HBsAg was found to decrease by $2.02 \mathrm{IU} / \mathrm{L}$ per a year increase in age (Figure 1). History of blood transfusion was significantly associated with anti-HBsAg (OR: 2.34, 95\% CI: 1.08 - 5.06, $\mathrm{P}=0.028$ (Table 3)).

\section{Discussion}

This is the first study to establish prevalence of anti-HBsAg among HIV patients attending CTC in a district hospital, Tanzania. The population studied had not been vaccinated against $\mathrm{HBV}$ and having the fact that universal HBV vaccination among infants started 6 years ago in Tanzania, the observed prevalence of anti-HBsAg strongly indicates the natural immunity following infections. The prevalence of anti-HBsAg in the current study is high compared to a previous studies in Manyara region and Iran which reported prevalence of $39 \%$ and $41.3 \%$, respectively [3] [14].

High prevalence of anti-HBsAg in this study could be explained by the fact that HIV and HBV share the same transmission route, therefore the prevalence of natural anti-HBsAg is expected to be significantly high in HIV population than in general population. In the contrary, when compared to the study done in Europe among intravenous drug users which reported the prevalence of $67.8 \%$

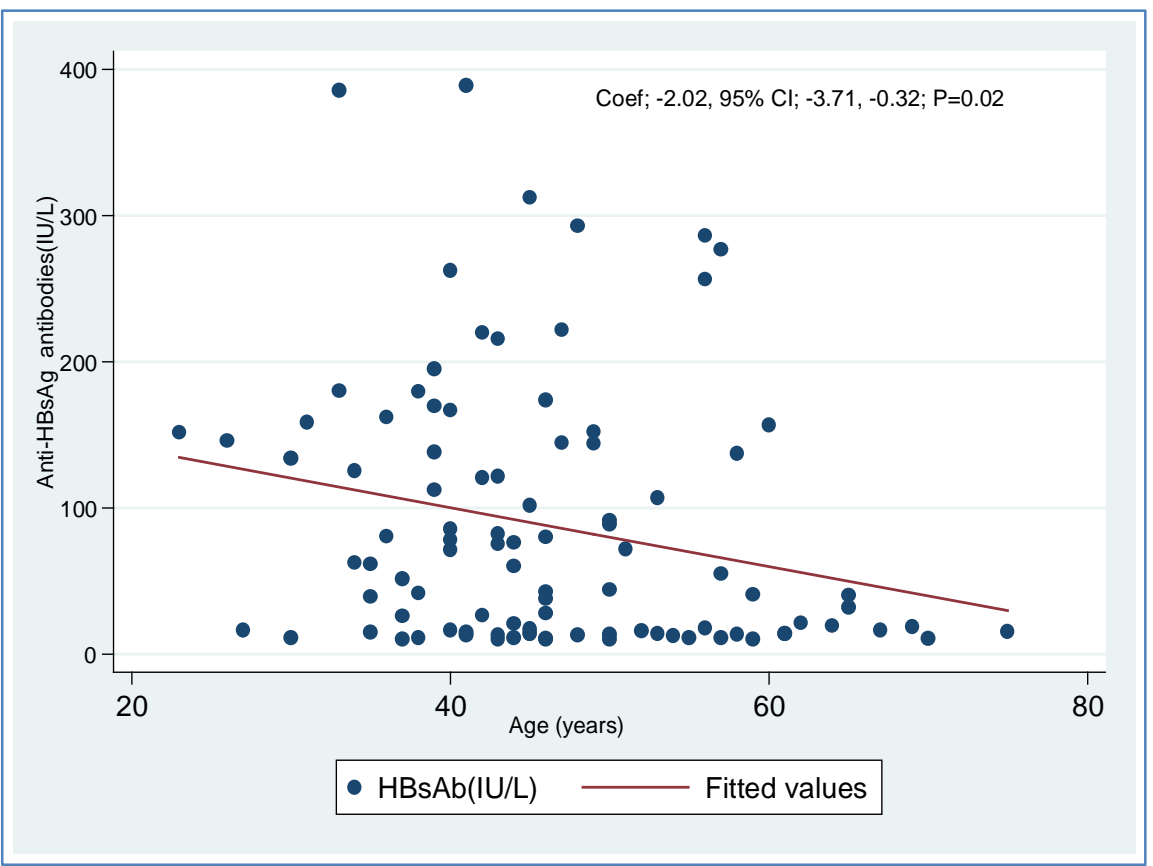

Figure 1. A year increase in age HBV natural antibodies decrease by $2.02 \mathrm{IU} / \mathrm{L}$. 
Table 3. Factors associated with anti-HBsAg among 243 HIV seropositive individuals at Sengerema DDH.

\begin{tabular}{|c|c|c|c|c|}
\hline \multirow[b]{2}{*}{ Variable (HBV Neg) } & \multirow[b]{2}{*}{ IR Positive } & \multirow[b]{2}{*}{ IR Negative } & \multicolumn{2}{|c|}{ Univariate regression } \\
\hline & & & OR [95\% CI] & $P$-value \\
\hline & Median/n(\%) & Median/n(\%) & & \\
\hline Age (Years) & 45 (IQR: 23 - 75) & 43 (IQR: 18 - 71) & $1.02[0.99-1.04]$ & 0.0572 \\
\hline \multicolumn{5}{|l|}{ Sex } \\
\hline Female & $69(43.05)$ & $88(56.05)$ & 1 & \\
\hline Male & $30(46.15)$ & $35(53.85)$ & $0.914[0.51-1.63]$ & 0.764 \\
\hline \multicolumn{5}{|l|}{ Transfusion } \\
\hline No & $79(41.58)$ & 1 & & \\
\hline Yes & $20(62.50)$ & $12(37.50)$ & $2.34[1.08-5.06]$ & 0.028 \\
\hline \multicolumn{5}{|l|}{ Tatooing } \\
\hline No & $22(44.0)$ & $28(56.0)$ & 1 & \\
\hline Yes & $77(44.77)$ & $95(55.23)$ & $1.03[0.54-1.94]$ & 0.923 \\
\hline \multicolumn{5}{|l|}{ Sharing devices } \\
\hline No & $93(44.2)$ & $117(55.71)$ & 1 & \\
\hline Yes & $6(50)$ & $6(50)$ & $1.25[0.39-4.02]$ & 0.699 \\
\hline \multicolumn{5}{|l|}{ CD4 Count } \\
\hline Low & $12(46.15)$ & $14(53.8)$ & 1 & \\
\hline Medium & $30(37.5)$ & $50(62.5)$ & $0.7[0.28-1.71]$ & 0.269 \\
\hline High & $57(49.14)$ & $59(50.8)$ & $1.12[0.48-2.64]$ & 0.783 \\
\hline \multicolumn{5}{|l|}{ STI } \\
\hline No & $62(42.18)$ & $85(57.82)$ & 1 & \\
\hline Yes & $37(49.33)$ & $38(50.67)$ & $1.33[0.76-2.33]$ & 0.311 \\
\hline
\end{tabular}

[8], the prevalence in this study is significantly low. This could be explained by the nature of the study population; intravenous drug users are more at risk of acquiring HBV than HIV infected individuals [15].

In the current study, history of blood transfusion was significantly associated with natural anti-HBsAg; being blood borne infection HBV can be easily transmitted through infected blood [16]. This calls for the need to put more emphasis on the current screening of blood before transfusion.

In this study, it has been observed that there is significantly decrease in anti-HBsAg titres with increase in age, necessitating the booster vaccination dose.

The prevalence of HBsAg which indicates acute/chronic HBV infection was comparable to previous study conducted in Kano State-Nigeria which reported the prevalence of $10.7 \%$ [13]. In comparison to the previous study conducted in Mwanza three years ago which reported the prevalence of $6.9 \%$ among HIV seropositive population in the city of Mwanza, Tanzania, the reported prevalence 
in the current study is slightly high, however the difference is not statistically significant [17]. Despite being not statistically significant, the higher prevalence in the district setting which is considered rural than in the city necessitate the need for more campaigns in the rural areas regarding STIs. Among the factors assesed, only being co-infected with HCV was found to predict HBsAg positivity. This observation is similar to the previous studies conducted in Thailand,Tehran-Iran and China [18] [19] [20]. The possible explanation could be the fact that all HBV, HCV and HIV shares the same transmission routes. However, these findings are different from previous studies which did not find any association with HCV coinfection [20].

Regarding HCV, the observed seroprevalence was high (8.2\%) according to WHO grading of HCV prevalence. Findings of the current study are similar to a range of $4 \%-10 \%$ observed among Nigerian adults at Lagos [21], Jos [22], Ibadan [23] and exactly similar to prevalence of $8.2 \%$ found in the Northern Nigeria [22]. The current prevalence is higher than $3.3 \%$ reported in a previous study at Mulago Hospital in Uganda [24]. Compared to previous studies in Tanzania, the observed prevalence in the current study is lower than $13.8 \%$ and $18.1 \%$ reported at Muhimbili National Hospital Muhimbili among children and adults HIV infected patients, respectively [25] [26]. Significantly, high prevalence was reported in Spain (33\%), USA (30\%), France (24.3\%) and Morocco (19.8\%) than in the present study [27] [28]; the differences could be explained by the differences in the population studied and the type assays used to detect HCV antibodies.

\section{Limitations}

One of the major limitations in this study is the failure to test for anti- $\mathrm{HBc}$ to confirm the natural infections.

\section{Conclusion and Recommendations}

The prevalence of HBV and HCV infections is high among HIV infected population in the rural setting of Tanzania. There is a need to sensitize campaigns of STIs prevention in rural areas. In addition, HBV vaccination programs should be expanded to HIV seropositive individuals.

\section{Acknowledgements}

The authors would like to acknowledge the technical support provided by Sengerema DDH staffs and the department of Microbiology and Immunology, CUHAS-Bugando.

\section{Author's Contributions}

MMM, BRK, VS and SEM participated in the design of the study. KJM, AM, JJM, EM and CAM participated in the data and sample collection. KJM, AM, JJM, HS, EM and VS performed serological tests. SEM, MMM and BRK analysed and interpreted the data. MMM wrote the first draft of the manuscript. SEM did 
a critical review of the manuscript. All authors read and approved the final version of the manuscript.

\section{Conflicts of Interest}

The authors declare that they have no competing interests.

\section{References}

[1] Mohammadi, M., et al. (2009) Survey of Both Hepatitis B Virus (HBsAg) and Hepatitis C Virus (HCV-Ab) Coinfection among HIV Positive Patients. Virology Journal, 6, 202. https://doi.org/10.1186/1743-422X-6-202

[2] Burnett, R.J. (2008) Hepatitis B Virus and Human Immunodeficiency Virus Co-Infection: Impact on Transmission and Natural History of Disease. Southern African Journal of Epidemiology and Infection, 23, 19-23. https://doi.org/10.1080/10158782.2008.11441295

[3] Hvitmyhr, C. and Otterstrøm, N. (2013) Hepatitis B Co-Infection among People Living with HIV/AIDS in Rural Tanzania. Dissertation, Universitetet i Oslo, Oslo.

[4] Burnett, R., et al. (2005) Hepatitis B Virus and Human Immunodeficiency Virus Co-Infection in Sub-Saharan Africa: A Call for Further Investigation. Liver international, 25, 201-213. https://doi.org/10.1111/j.1478-3231.2005.01054.x

[5] WHO (2009) Hepatitis C. Fact Sheet No. 164.

[6] Madhava, V., Burgess, C. and Drucker, E. (2002) Epidemiology of Chronic Hepatitis C Virus Infection in Sub-Saharan Africa. The Lancet Infectious Diseases, 2, 293-302. https://doi.org/10.1016/S1473-3099(02)00264-5

[7] Zaltron, S., et al. (2012) Chronic HCV Infection: Epidemiological and Clinical Relevance. BMC Infectious Diseases, 12, S2. https://doi.org/10.1186/1471-2334-12-S2-S2

[8] Rodriguez-Mendez, M., et al. (2000) Prevalence, Patterns, and Course of Past Hepatitis B Virus Infection in Intravenous Drug Users with HIV-1 Infection. The American Journal of Gastroenterology, 95, 1316-1322. https://doi.org/10.1111/j.1572-0241.2000.01981.x

[9] Kashala, O., et al. (1994) Hepatitis B Virus Activation among Central Africans Infected with Human Immunodeficiency Virus (HIV) Type 1: Pre-s2 Antigen Is Predominantly Expressed in HIV Infection. Journal of Infectious Diseases, 169, 628-632. https://doi.org/10.1093/infdis/169.3.628

[10] Kallestrup, P., et al. (2003) Low Prevalence of Hepatitis C Virus Antibodies in HIV-Endemic Area of Zimbabwe Support Sexual Transmission as the Major Route of HIV Transmission in Africa. AIDS, 17, 1400-1402. https://doi.org/10.1097/00002030-200306130-00019

[11] Adewole, O.O., et al. (2009) Hepatitis B and C Virus Co-Infection in Nigerian Patients with HIV Infection. The Journal of Infection in Developing Countries, 3 , 369-375. https://doi.org/10.3855/jidc.245

[12] Nagu, T.J., Bakari, M. and Matee, M. (2008) Hepatitis A, B and C Viral Co-Infections among HIV-Infected Adults Presenting for Care and Treatment at Muhimbili National Hospital in Dar es Salaam, Tanzania. BMC Public Health, 8, 416. https://doi.org/10.1186/1471-2458-8-416

[13] Imoru, M., Eke, C. and Adegoke, A. (2003) Prevalence of Hepatitis-B Surface Antigen (HbsAg), Hepatitis C Virus (HCV) and Human Immunodeficiency Virus (HIV) among Blood Donors in Kano State, Nigeria. Journal of Medical Laboratory 
Science, 12, 59-63.

[14] Koziel, M.J. and Peters, M.G. (2007) Viral Hepatitis in HIV Infection. New England Journal of Medicine, 356, 1445-1454. https://doi.org/10.1056/NEJMra065142

[15] Shapatava, E., et al. (2006) Risk Behaviors and HIV, Hepatitis B, and Hepatitis C Seroprevalence among Injection Drug Users in Georgia. Drug and Alcohol Dependence, 82, S35-S38. https://doi.org/10.1016/S0376-8716(06)80006-2

[16] Phoon, W.-O., Fong, N.-P. and Lee, J. (1988) History of Blood Transfusion, Tattooing, Acupuncture and Risk of Hepatitis B Surface Antigenaemia among Chinese men in Singapore. American Journal of Public Health, 78, 958-960. https://doi.org/10.2105/AJPH.78.8.958

[17] Mirambo, M.M., et al. (2015) Treponema Pallidum and Hepatitis B Virus Co-Infection among HIV Infected Patients in Mwanza City. East African Journal of Public Health, 12, 997-1000.

[18] Sungkanuparph, S., et al. (2004) Prevalence of Hepatitis B Virus and Hepatitis C Virus Co-Infection with Human Immunodeficiency Virus in Thai Patients: A Tertiary-Care-Based Study. Journal of the Medical Association of Thailand, 87, 1349-1354.

[19] Rahimi-Movaghar, A., Razaghi, E.M., Sahimi-Izadian, E. and Amin-Esmaeili, M. (2010) HIV, Hepatitis C Virus, and Hepatitis B Virus Co-Infections among Injecting Drug Users in Tehran, Iran. International Journal of Infectious Diseases, 14, e28-e33. https://doi.org/10.1016/j.ijid.2009.03.002

[20] Zhang, F., et al. (2014) HIV, Hepatitis B Virus, and Hepatitis C Virus Co-Infection in Patients in the China National Free Antiretroviral Treatment Program, 2010-12: A Retrospective Observational Cohort Study. The Lancet Infectious Diseases, 14, 1065-1072. https://doi.org/10.1016/S1473-3099(14)70946-6

[21] Lesi, O., Kehinde, M., Oguh, D.N. and Amira, O. (2007) Hepatitis B and C Virus Infection in Nigerian Patients with HIV/AIDS. The Nigerian Postgraduate Medical Journal, 14, 129-133.

[22] Agwale, S.M., et al. (2004) Prevalence of HCV Coinfection in HIV-Infected Individuals in Nigeria and Characterization of HCV Genotypes. Journal of Clinical Virology, 31, 3-6. https://doi.org/10.1016/j.jcv.2004.09.001

[23] Otegbayo, J.A., et al. (2008) Prevalence of Hepatitis B and C Seropositivity in a Nigerian Cohort of HIV-Infected Patients. Annals of Hepatology, 7, 152-156.

[24] Walusansa, V. and Kagimu, M. (2009) Screening for Hepatitis C among HIV Positive Patients at Mulago Hospital in Uganda. African Health Sciences, 9, 143-146.

[25] Nagu, T.J., Bakari, M. and Matee, M. (2008) Hepatitis A, B and C Viral Co-Infections among HIV-Infected Adults Presenting for Care and Treatment at Muhimbili National Hospital in Dar es Salaam, Tanzania. BMC Public Health, 8, 416. https://doi.org/10.1186/1471-2458-8-416

[26] Telatela, S.P., Matee, M.I. and Munubhi, E.K. (2007) Seroprevalence of Hepatitis B and C Viral Co-Infections among Children Infected with Human Immunodeficiency Virus Attending the Paediatric HIV Care and Treatment Center at Muhimbili National Hospital in Dar-es-Salaam, Tanzania. BMC Public Health, 7, 338. https://doi.org/10.1186/1471-2458-7-338

[27] Chung, R. (2004) Management of HIV/HCV Coinfection. The PRN Notebook, 9, 14-19.

[28] Larsen, C., et al. (2008) Prevalence of Hepatitis C and Hepatitis B Infection in the HIV-Infected Population of France, 2004. Eurosurveillance, 13, 109-112. 